\title{
CASOS DE BRISAS VALE / MONTANHA NO INTERIOR ALAGOANO NA ESTAÇÃO DO VERÃO
}

\author{
Isidro M. T. J. Ihadua, Roberto F. F. Lyra, Diogo N. S. Ramos, José Davi O. Moura
}

\section{RESUMO}

O objetivo foi avaliar os casos de brisas Vale/ montanha entre 2 regiões distintas, agreste e sertão alagoano. A série de medidas anemométricas utilizada foi dos meses de Janeiro, fevereiro e Desembro de 2008. Verificou-se um maior número de caso de brisa em Palmeira dos Índios (agreste), com intensidade do vento maior que em Água Branca (sertão). As brisas são frequentes de madrugada e no horário de transição da (00:00 a 11:50).

\section{ABSTRACT}

The objective was to evaluate the cases of vale/mountain breezes between two distinct regions, agreste and sertão alagoan. The series of measures anemometric was used during January, February and December 2008. There were a greater number of cases of breezes in Palmeira dos Indios (agreste) with wind speed higher than in Água Branca (sertão). The breezes are frequent in the early morning and at the time of transation from (00:00 to 11:50).

\section{INTRODUÇÃO}

Durante a noite, a montanha tem um arrefecimento intenso, gerando uma circulação de ar fresco vindo da montanha para o vale, ao longo da encosta, o que conhecemos como brisa de montanha (SILVA, 2009).

O objetivo deste trabalho é identificar os casos de brisas vale montanha no interior do estado alagoano.

\section{METODOLOGIA}

Dados anemométricos dos meses de janeiro, fevereiro e dezembro de 2008 dos sítios de Palmeira dos Índios (agreste) e Água Branca (sertão) foram utilizados neste estudo.

Tabela 1- Coordenadas geográficas e informações das torres anemométricas.

\begin{tabular}{|c|c|c|c|c|}
\hline Local & Latitude & Longitude & $\begin{array}{c}\text { Altitude } \\
(\mathbf{m})\end{array}$ & $\begin{array}{c}\text { Altura da } \\
\text { torre (m) }\end{array}$ \\
\hline Á. Branca & $-9,23985$ & $-37,93555$ & 738 & 50 \\
\hline P. dos Índios & $-9,30318$ & $-36,68697$ & 649 & 100 \\
\hline
\end{tabular}

\section{Algoritmo para identificação de brisas vale-montanha}

A partir da direção predominante de sudeste em Água Branca, criou-se o algoritmo em que foi considerado de limite inferior (230 graus) e o ângulo de 50 graus (nordeste). Para P. dos Índios com a direção de vento predominante de leste, então foi considerado a partir de 230 graus o limite inferior e o ângulo de 25 graus, tendo como referencia o eixo norte para 
ambos os locais. O vento que teve direção oposta à direção predominante e entre o limite inferior e o ângulo foi considerado de brisa Vale/ montanha.

a)

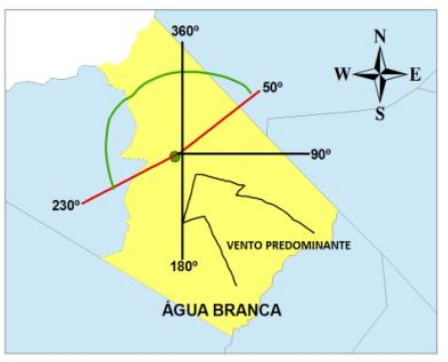

b)

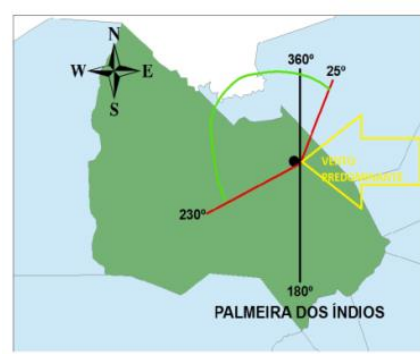

Figura 2 - Determinação do limite inferior e do ângulo a partir do eixo norte e em relação à direção do vento predominante.

\section{DISCUSSÃO DOS RESULTADOS}

Com o algoritmo desenvolvido, Palmeira dos Índios foi o sítio com o maior número de casos de brisas, tanto de vale como de montanha. Justifica-se pela proximidade do litoral e com terreno bastante acidentado com vales profundos em direção a torre 3 (figura 3b).

Tabela 2: Número de casos identificados de brisa de montanha.

\begin{tabular}{|c|c|c|}
\hline \multirow{2}{*}{ Meses } & \multicolumn{2}{|c|}{ Casos de Brisas de Montanha } \\
\cline { 2 - 3 } & Água Branca & Palmeira dos Indios \\
\hline Jan. & 9 & 103 \\
\hline Fev. & 33 & 104 \\
\hline Dez. & 87 & 105 \\
\hline
\end{tabular}

$\mathrm{Na}$ figura 3, ilustra o relevo dos pontos estudados. Nela observamos vales adentrando literalmente no continente e com terreno bastante acidentado. Na figura $3 \mathrm{~b}$ o ar durante a noite é acelerado ao longo do vale desde a costa e de outras reentrâncias, atingindo o local onde está torre 3. No entanto, devido a este sistema convergente de vales faz afluir o ar frio com altíssimas velocidades. Vale enfatizar que Palmeiro dos Índios está mais próxima da costa (142 quilômetros). Diferente da figura 3a o escoamento não atinge diretamente o ponto (torre 1) e com uma distancia de 224 quilômetros da costa.

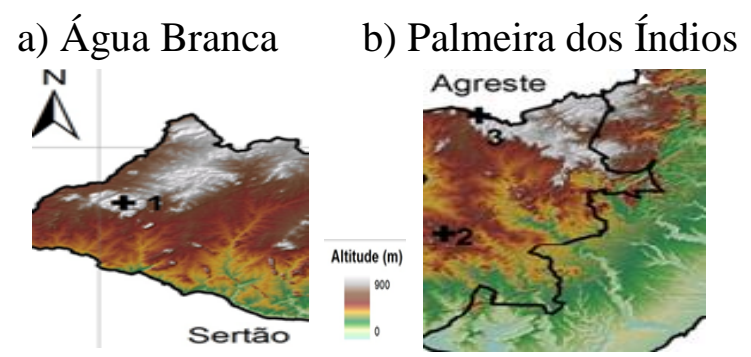

Figura 3- Relevo e localização das torres anemométricas (+) no Agreste (Palmeiro dos Índios) e no Sertão (Água Branca). 
Apesar da diferença numérica o padrão é o mesmo, ou seja, maior percentual de casos foi de madrugada (00:00 as 05:50) seguido pelo período da manhã (06:00 as 11:50). Entretanto, em termos percentual Água branca teve maior frequência de brisas de vale no período das 12:00 as 17:50. Vale salientar que a maioria dos casos de brisas de montanha computados no período diurno se concentrou nos horários de transição, ou seja, nas primeiras horas da manhã e nas últimas horas da tarde (figura 4).

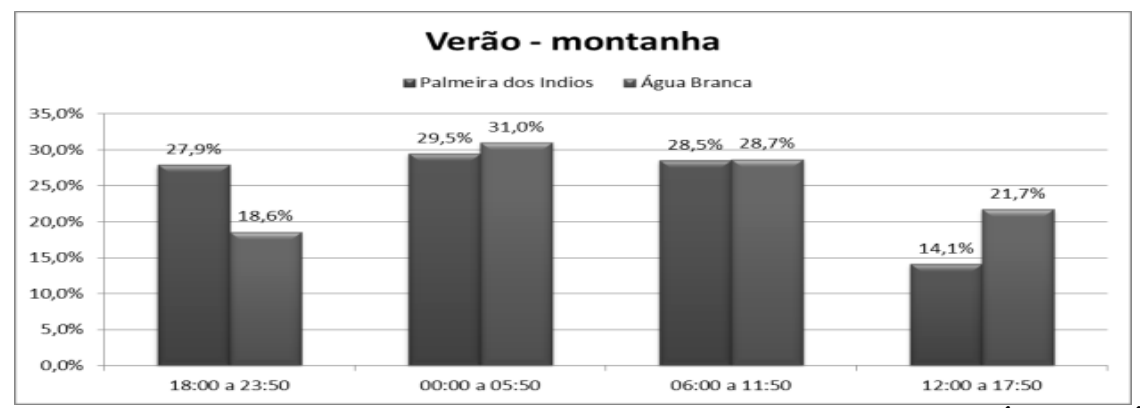

Figura 4- Percentual de casos de brisas nos 4 intervalos de 6 horas em P. dos Índios e Á. Branca, no verão do ano de 2008.

\section{CONCLUSÕES}

De acordo com os resultados, conclui-se que o algoritmo teve êxitos no uso de obtenção de brisas. Em função da equação do vento constatou-se que todos os casos de brisas estiveram dentro do limite do algoritmo. Palmeira dos Índios teve maior número de casos de brisas de montanha. Água Branca obteve maior frequência de brisas de vale.

\section{AGRADECIMENTO}

UFAL - Universidade Federal de Alagoas

\section{REFERÊNCIA BIBLIOGRÁFICA}

SILVA, A.R. Estudo observacional do regime de vento no Estado de Alagoas, nos períodos seca e de transição seco-chuvoso. 2009, 100p. Trabalho de Conclusão (Bacharelado em Meteorologia), UFAL, Maceió. 